\title{
Prostate Biopsy Using Transrectal Ultrasonography; The Optimal Number of Cores Regarding Cancer Detection Rate and Complications
}

\author{
Mahyar Ghafoori ${ }^{1,2,}$; Meysam Velayati ${ }^{1}$; Mounes Aliyari Ghasabeh ${ }^{2}$; Madjid Shakiba ${ }^{2}$; \\ Manijeh Alavi ${ }^{3}$
}

${ }^{1}$ Department of Radiology, Hazrat Rasoul Akram Hospital, School of Medicine, Iran University of Medical Sciences, Tehran, IR Iran

${ }^{2}$ Advanced Diagnostic and Interventional Radiology Research Center, Tehran University of Medical Sciences, Tehran, IR Iran

${ }^{3}$ Deputy of Research and Technology, Ministry of Health and Medical Education, Tehran, IR Iran

*Corresponding author: Mahyar Ghafoori, Department of Radiology, Hazrat Rasoul Akram Hospital, School of Medicine, Iran University of Medical Sciences, Tehran, IR Iran. Tel: +982166509057, Fax:+98-2166517118, E-mail: mahyarghafoori@gmail.com

Received: June 27, 2013; Accepted: October 3, 2013

\begin{abstract}
Background:Transrectal ultrasound guided biopsy of the prostate is the most common modality used to diagnose prostate cancer. Objectives: The aim of this study was to evaluate the optimal number of cores at prostate biopsy, which have the most diagnostic value with least adverse effects.

Patients and Materials: Transrectal ultrasonography (TRUS) guided biopsy was performed in 180 patients suspicious for prostate cancer due to either abnormal rectal examination or elevated PSA. The patients were divided randomly into three groups of six-core, twelvecore and eighteen-core biopsies. The detection rate of prostate cancer in each group with the rate of post biopsy urinary infection and prostatitis were compared.

Results: Prostate cancerwas diagnosed in 8(13.3\%), 21(35\%)and 24(40\%) patients in six, twelve and eighteen core biopsygroups, respectively. Urinary tract infection and prostatitis occurred in 17 (28.3\%),23(38.3\%)and $35(58.3 \%)$ patients in six, twelve and eighteen core biopsy groups, respectively. Considering the detection rate of prostate cancer, there was a significant difference between 6 and 12 core biopsy groups $(\mathrm{P}=$ 0.006) and 12-core biopsies detected more cases of prostate cancer, but there was no significant difference between 12 and 18 core biopsy groups $(\mathrm{P}=0.572)$. Considering the infection rate, there was no significant difference between 6 and 12 core biopsy groups $(P=0.254)$, but there was a significant difference between 12 and 18 core biopsy groups $(\mathrm{P}=0.028)$ and infectious complications occurred more frequently in 18-core biopsy group.

Conclusions: The best balance between detection rate of prostate cancer and infectious complications of biopsies achieved in twelve-core biopsy protocol. Twelve-core biopsy enhances the rate of prostate cancer detection with minimum adverse effects.
\end{abstract}

Keywords: Cancer; Prostate; Biopsy; Adverse Effects

\section{Background}

Prostate cancer is the most common cancer in men (1). Most prostate cancers are slow growing, but aggressive prostate cancers are also seen $(2,3)$. Prevalence of prostate cancer varies widely across the world, but it is more common in developed countries $(4,5)$. It is the second leading cause of cancer-related death in men in the United States and the sixth cause of cancer-related death globally (4, $6,7)$. Many cases of prostate cancers remain subclinical and never have symptoms (8) or have been symptomatically in progressive stage of disease (9). Therefore, using screening method to detect cancer in curable stage of disease is very important. Prostate cancer screening options include digital rectal examination (DRE) and prostate specific antigen (PSA) blood test $(10,11)$. These screening may lead to biopsy, which is the only test able to confirm the diagnosis of prostate cancer performed via transrectal ultrasonography (TRUS) (11-15). The common protocol used in TRUS guided prostate biopsy is sextant biopsy proposed by Hodge et al. in the late eighties $(16,17)$. However in the last decade, several studies were designed to evaluate prostate cancer detecting performance by TRUS guided prostate biopsy with more than six biopsies either from other sites of prostate or repeating biopsy in the six previous areas (18-21). The results of studies confirmed the hypothesis that greater numbers of biopsies increases the diagnostic power. On the other hand, each biopsy leads to complications such as hematuria (14.5\%), hematospermia (6.5\%-74.4\%), dysuria (minor complications) and severe complications such as infection and fever episode (6.6\%), urinary retention (0-4.6\%) and septicemia (rarely) (22), so increasing the number of biopsies increases the adverse effects (23).

\section{Objectives}

In this study, we evaluated three most popular biopsy protocols: 6-core prostate biopsy, 12-core prostate biopsy

Copyright ( ) 2015, Tehran University of Medical Sciences and Iranian Society of Radiology. This is an open-access article distributed under the terms of the Creative Commons Attribution-NonCommercial 4.0 International License (http://creativecommons.org/licenses/by-nc/4.0/) which permits copy and redistribute the material just in noncommercial usages, provided the original work is properly cited. 
and 18-core prostate biopsy to determine which protocol has the most diagnostic value for detection of prostate cancer with least adverse effects.

\section{Patients and Methods}

This study was performed as a randomized clinical trial study between April 2011 and March 2012 on patients suspicious for prostate cancer candidate for TRUS guided prostate biopsy due to abnormal digital rectal examination (DRE) and/or elevation of prostate specific antigen (PSA) referred from urology ward to radiology department of Hazrat Rasoul Akram Hospital. Patients who had a history of previous biopsy, history of prostatic TUR due to BPH, symptoms and signs of urinary tract infections and receiving antibiotic treatment for any reason were excluded from the study. The ultrasound machine was Esaote Mylab 70 XVG (Genoa, Italy) with a multifrequency endocavitary transducer (EC123, 7-10 $\mathrm{MHz}$ ) equipped with biopsy guide and biopsy specimens obtained with automatic biopsy gun with 18 gauge TruCut needle. In total, 180 patients entered the study and divided into three groups by block randomization:1) In the first group, six specimens obtained from the prostate gland considering the following protocol: dividing the prostate to six segments and obtaining biopsies from base, middle and apex of the peripheral zone at both sides of prostate. 2) In the second group, 12 specimens obtained from the prostate gland considering the following protocol: dividing the prostate to eight segments including base, upper-mid, lower-mid and apex in either sides of prostate and obtaining one biopsy specimen from base and apex segments and obtaining two specimens in middle segments; one more medially (including the peripheral zone and inner gland) and one more laterally (pure peripheral zone).3) In the third group, 18 specimens obtained from the prostate gland considering the following protocol: dividing the prostate to eight segments similar to the second group and obtaining two biopsy specimens from each segment plus additional biopsies from periurethral inner gland in each side. All patients received antibiotic prophylaxis as follows: Metronidazole 250 mg every eight hours and Ciprofloxacin 500 mg every 12 hours, from two days before to five days after the biopsy, also $500 \mathrm{mg}$ of Amikacin was administered by intravenous infusion, 6 and 1 hour before biopsy. All biopsies in all three groups were performed by the same radiologist. Forty-eight hours after biopsies, patients were asked about signs of urinary tract infection and prostatitis especially dysuria. Patients temperature was checked and urine sample was collected for urine analysis (U/A) and urine culture $(\mathrm{U} / \mathrm{C})$. The frequency of positive cancer patients and infectious complications were compared between the three groups. The objectives and methods of the study were explained to all subjects and a written informed consent was obtained.

\subsection{Statistical Analysis}

Statistical analysis was performed by SPSS ver 16 (IBM, USA). Variables were reported as means \pm standard deviations. Normality of variables was checked using the Kolmogorov-Smirnov test. Comparison between groups was performed using Analysis of variance [ANOVA] and chi-square tests. P value lower than 0.05 was considered statistically significant.

\section{Results}

Patients mean age in 6-core biopsy group was $58.4 \pm 7.8$ years, in 12-core biopsy group was $57.6 \pm 8.6$ years and in 18-core biopsy group was $58.7 \pm 8$ years. There was no significant difference in mean age between the groups ( $\mathrm{P}=$ 0.731). Mean PSA level of patients in 6-core biopsy group was $8.7 \pm 4.6 \mathrm{ng} / \mathrm{mL}$, in 12-core biopsy group was $7.9 \pm 4.3$ $\mathrm{ng} / \mathrm{mL}$ and in 18-core biopsy group was $8.6 \pm 4.2 \mathrm{ng} / \mathrm{mL}$. There was no significant difference in mean PSA level between the groups $(\mathrm{P}=0.617)$.

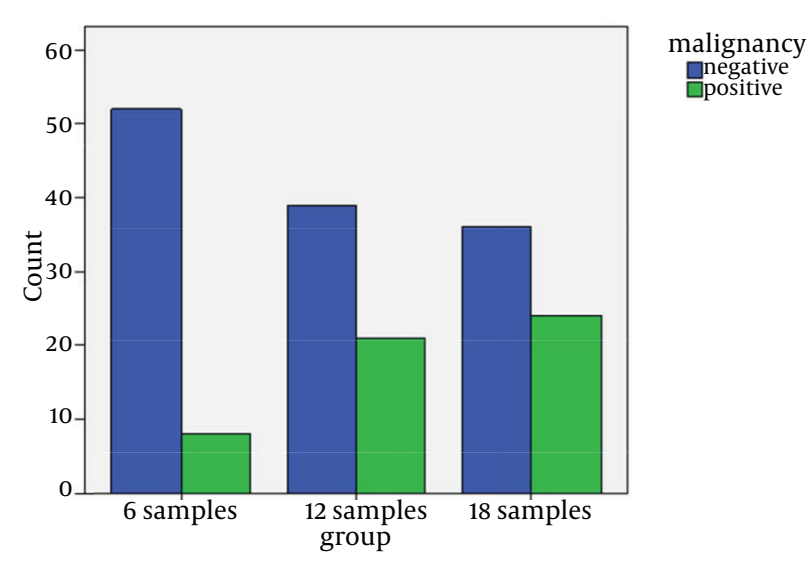

Figure 1. Comparing the frequency of diagnosed prostate cancer between different biopsy groups

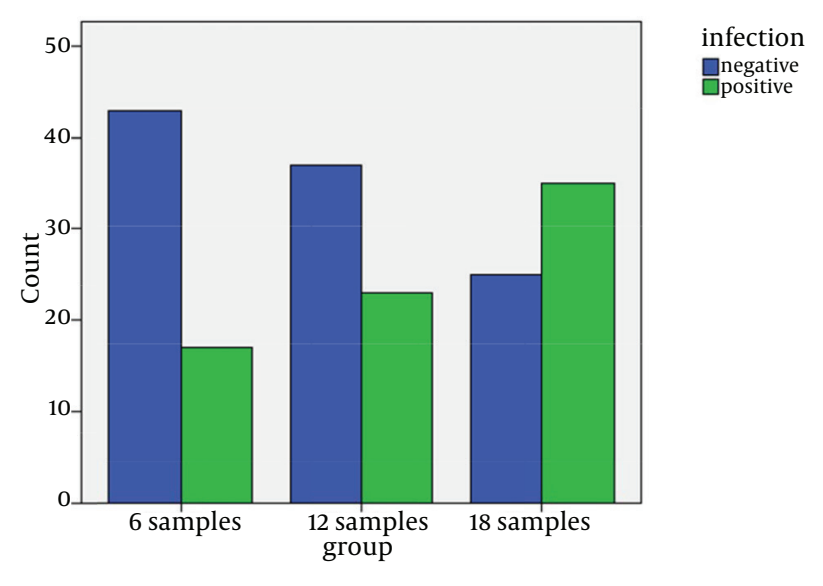

Figure 2. Comparing the frequency of infection in different groups 
Histological results obtained from TRUS guided prostate biopsy showed that in 6-core biopsy group, eight (13.3\%) of 60 patients had positive biopsy results for prostate cancer. In 12-core biopsy group, 21 (35\%) of 60 patients had positive biopsy results for prostate cancer. In 18-core biopsy group, 24 (40\%) of 60 patients had positive biopsy results for prostate cancer $(\mathrm{P}=0.003)$ (Figure 1$)$.

Binary comparison of prostate biopsy results between each two groups indicated a significant difference in the detection of prostate cancer between 6-core biopsy and 12-core biopsy $(\mathrm{P}=0.006)$. Besides, there was a significant difference in detection of prostate cancer between 6-core biopsy and 18-core biopsy ( $\mathrm{P}=0.001)$, but there was no significant difference in the detection of prostate cancer between 12-core biopsy and 18-core biopsy $(\mathrm{P}=0.572)$. In this study, infection rate as one of the most important adverse effects of prostate biopsy was evaluated. In 6-core biopsy group, infection occurred in 17 patients (28.3\%); in 12-core biopsy group infection occurred in 23 (38.3\%) patients and in 18-core biopsy group infection occurred in $35(58.3 \%)$ patients $(\mathrm{P}=0.003)$ (Figure 2$)$.

Pair wise comparison of infection rate between each two groups indicated no significant difference in infection rate between 6-core biopsy group and 12-core biopsy group $(P=0.254)$, but there was a significant difference in infection rate between 12-core biopsy group and 18-core biopsy group $(\mathrm{P}=0.028)$ as well as 6 -core biopsy group and 18-core biopsy group $(\mathrm{P}=0.001)$.

\section{Discussion}

The desirable number of obtained biopsies to detect all, or at least most prostate cancers has not yet ratified. In the early 1990s, use of sextant biopsies involving six cores, three from each side of the prostate gland, became the standard approach for the diagnosis of prostate cancer (24-26); but as studies showed that this strategy misses a significant number of prostate cancer (high false-negative rates), hypotheses were proposed to increase the number of biopsies since the late 1990s. While there is disagreement about the optimal strategy, several studies showed that more number of biopsies resulted in detection of about $10-30 \%$ more cancers than the conventional sextant biopsy (27-31). On the other hand by increasing the number of biopsies, increasing adverse effects, especially infection and prostatitis as the major and lifethreatening complications were unavoidable (32).

In our study, we tried to minimize confounding factors that may interfere with the study results, therefore effective factors of malignancy such as age and PSA level became identical in all the three groups of study. There was no statistically significant difference between age as well as PSA level between the three group of patients $(\mathrm{P}=0.731$, $\mathrm{P}=0.617$, respectively). Results of our study showed that detecting rate of prostate cancer in 12-core biopsy protocol was more than 6-core biopsy protocol with a significant statistical difference between the results. Although 18-core biopsy protocol detected prostate cancer more than 6-core biopsy, but the difference between 12-core and 18-core biopsy protocols was not statistically significant. In a similar study by Thiesler et al.(33) on 241 patients suspicious for prostate cancer, diagnostic power of 12-core biopsy method was evaluated compared with standardized six-core biopsy method. In this study, the amount of PSA level was less than $4 \mathrm{ng} / \mathrm{mL}$, while the average of PSA level in our study was $8.4 \pm 4.3 \mathrm{ng} / \mathrm{mL}$. Results of this study showed that $34 \%$ (81/241) of patients who underwent 6-core TRUS guided biopsy had prostate cancer; whereas, an additional $23.5 \%$ (19/81) of cancers were diagnosed using the 12-core biopsy protocol, so in low PSA level ( $<4 \mathrm{ng} /$ $\mathrm{mL}), 12$-core biopsy is more appropriate than six core biopsy. Our study expressed that increasing the number of biopsies from 6 to 12 increased cancer detection rate (35\% versus 13.3\%), but increasing 12 to 18 -core biopsy resulted in no statistically significant difference for detection of can$\operatorname{cer}(\mathrm{P}=0.572)$. Guichard et al. (20) in a study designed prospectively evaluated the diagnostic yield of 6-core biopsy, 12-core biopsy, 18- core biopsy and 21 core biopsy protocol in prostate cancer. In his study, cancer detection rates using 6-core biopsy protocol was $31.7 \%$, for 12-core biopsy was $38.7 \%$ and for 18 and 21 core biopsies were $41.5 \%$, and $42.5 \%$, respectively. The 12 -core protocol improved the cancer detection rate by $22 \%$ compared with the 6 -core protocol $(\mathrm{P}=0.0001)$. 18-core biopsy compared with 12-core biopsy scheme increased the diagnostic yield by $7.2 \%$ ( $\mathrm{P}=$ 0.023). In Guichard study, there were statistically significant differences between 12 and 18 core biopsies, which is in contrast with our study. This difference may be due to difference of PSA level distribution in both studies. In our study, mean PSA level was almost the same in each three groups, but in Guichard study patients were divided into three subgroups according to PSA level (PSA $\leq 4 \mathrm{ng} / \mathrm{mL}, 4$ $<$ PSA $<20$, PSA $\geq 20 \mathrm{ng} / \mathrm{mL}$ ). In recent years, increasing the number of biopsies played such an important role in detection of prostate cancer in such a way that saturation biopsy was used to detect prostate cancer with a more accuracy (In general, saturation biopsy is considered as a minimum of 20 cores taken from the prostate). Although, the usefulness of this approach is unset (34). There are several studies such as Kojima et al. (35), Matsumoto et al. (36), Terris et al. (37), Stamatiou et al. (18), Taylor et al. (38) and Eskew et al. (30) studies, which all have consensus on usefulness of increasing the number of specimens more than 6-core biopsy to increase the power of prostate cancer detection. However, the optimum number of biopsies required to detect prostate cancer is still largely unknown. In contrast, there are a few studies in which there are not statistically significant differences between 6-core biopsy, 12-core and 18-core biopsy in prostate cancer detection (39, 40). Furthermore, our study investigated the most important complication of biopsy as infection; 12-core biopsy protocol resulted in 38.3\% urinary tract infection and fever versus $28.3 \%$ infection rate in 6-core biopsy protocol, which was not statistically significant $(\mathrm{P}=0.254)$. 
Nevertheless, infection rate in 18-core biopsy protocol was $58.3 \%$, which had a statistically significant difference with 12-core and 6-core biopsy protocols, respectively ( $\mathrm{P}=0.028$ and $\mathrm{P}=0.001)$. Eichler in his systematic review of cancer detection rates and complications of various prostate biopsy approaches in 20698 patients stated that 12 core biopsy approach seems to have optimum balance between the cancer detection rate and biopsy complications (27). In addition, the study designed by Simon and colleagues demonstrated that adding the number of biopsy did not improve detection rate of cancer, it leads to increased morbidity and adverse effects, especially infection (41). Our study results showed that increasing the number of obtained biopsies from 6 to 12 is logical and increased the detection rate of prostate cancer significantly, but further increase in the number of biopsy specimens from 12 to 18 only increased post biopsy infectious complications without significant increase in cancer detection rate. We concluded that the optimum number of obtained prostate biopsies to reach acceptable diagnostic power with least infection rate is 12-core biopsy.

\section{Acknowledgements}

This study was an approved research project in Tehran University of Medical Sciences and supported by a grant from this university.

\section{Funding/Support}

This study was an approved research project in Tehran University of Medical Sciences and supported by a grant from this university.

\section{References}

1. Gilliland F, Becker TM, Smith A, Key CR, Samet JM. Trends in prostate cancer incidence and mortality in New Mexico are consistent with an increase in effective screening. Cancer Epidemiol Biomarkers Prev. 1994;3(2):105-11.

2. Lister S. Urine test could speed treatment of prostate cancer.London: The Sunday Times; 2009.

3. Hricak H, Choyke PL, Eberhardt SC, Leibel SA, Scardino PT. Imaging prostate cancer: a multidisciplinary perspective. Radiology. 2007;243(1):28-53.

4. Siegel R, Ward E, Brawley O, Jemal A. Cancer statistics, 2011: the impact of eliminating socioeconomic and racial disparities on premature cancer deaths. CA Cancer J Clin. 2011;61(4):212-36.

5. Baade PD, Youlden DR, Krnjacki LJ. International epidemiology of prostate cancer: geographical distribution and secular trends. Mol Nutr Food Res. 2009;53(2):171-84.

6. Wang P, Guo YM, Liu M, Qiang YQ, Guo XJ, Zhang YL, et al. A metaanalysis of the accuracy of prostate cancer studies which use magnetic resonance spectroscopy as a diagnostic tool. Korean J Radiol. 2008;9(5):432-8.

7. Haider MA, van der Kwast TH, Tanguay J, Evans AJ, Hashmi AT, Lockwood G, et al. Combined T2-weighted and diffusion-weighted MRI for localization of prostate cancer. AJR Am J Roentgenol. 2007;189(2):323-8.

8. Djulbegovic M, Beyth RJ, Neuberger MM, Stoffs TL, Vieweg J Djulbegovic B, et al. Screening for prostate cancer: systematic review and meta-analysis of randomised controlled trials. BMJ. 2010;341:c4543.

9. Tenke P, Horti J, Balint P, Kovacs B. Prostate cancer screening. Recent Results Cancer Res. 2007;175:65-81.
10. Thompson IM, Pauler DK, Goodman PJ, Tangen CM, Lucia MS, Parnes HL, et al. Prevalence of prostate cancer among men with a prostate-specific antigen level $<$ or $=4.0 \mathrm{ng}$ per milliliter. $\mathrm{N}$ Engl $\mathrm{J}$ Med. 2004;350(22):2239-46.

11. Brossner C, Bayer G, Madersbacher S, Kuber W, Klingler C, Pycha A. Twelve prostate biopsies detect significant cancer volumes (> $0.5 \mathrm{~mL}$ ). BJU Int. 2000;85(6):705-7.

12. McConnell JD, Bruskewitz R, Walsh P, Andriole G, Lieber M, Holtgrewe HL, et al. The effect of finasteride on the risk of acute urinary retention and the need for surgical treatment among men with benign prostatic hyperplasia. Finasteride Long-Term Efficacy and Safety Study Group. N Engl J Med.1998;338(9):557-63.

13. Emiliozzi P, Corsetti A, Tassi B, Federico G, Martini M, Pansadoro V Best approach for prostate cancer detection: a prospective study on transperineal versus transrectal six-core prostate biopsy. Urology. 2003;61(5):961-6.

14. Ito K, Ichinose Y, Kubota Y, Imai K, Yamanaka H. Clinicopathological features of prostate cancer detected by transrectal ultrasonography-guided systematic six-sextant biopsy. Int J Urol. 1997;4(5):474-9.

15. Lee SH, Chen SM, Ho CR, Chang PL, Chen CL, Tsui KH. Risk factors associated with transrectal ultrasound guided prostate needle biopsy in patients with prostate cancer. Chang Gung Med J. 2009;32(6):623-7.

16. Hodge KK, McNeal JE, Terris MK, Stamey TA. Random systematic versus directed ultrasound guided transrectal core biopsies of the prostate. J Urol.1989;142(1):71-4.

17. Hodge KK, McNeal JE, Stamey TA. Ultrasound guided transrectal core biopsies of the palpably abnormal prostate. J Urol. 1989;142(1):66-70.

18. Stamatiou K, Alevizos A, Karanasiou V, Mariolis A, Mihas C, Papathanasiou $M$, et al. Impact of additional sampling in the TRUS-guided biopsy for the diagnosis of prostate cancer. Urol Int. 2007;78(4):313-7.

19. Miyake H, Harada K, Inoue TA, Takenaka A, Hara I, Fujisawa M. Additional sampling of dorsal apex on systematic prostate biopsy: impact on early detection of prostate cancer. Urology. 2007;69(4):738-42.

20. Guichard G, Larre S, Gallina A, Lazar A, Faucon H, Chemama S, et al. Extended 21-sample needle biopsy protocol for diagnosis of prostate cancer in 1000 consecutive patients. Eur Urol. 2007;52(2):430-5.

21. Slongo LE, Sugisawa MC, Ioshii SO, Filho RT, Rocha LC. Efficiency of 6- and 12-punctures biopsies to detect prostate cancer in patients with PSA $<\mid=10 \mathrm{ng} / \mathrm{mL}$ and normal digital rectal examination. Int Braz J Urol. 2003;29(1):24-9.

22. The European Association of Urology Nurses.. Evidence-based Guidelines for Best Practice in Health Care Transrectal Ultrasound Guided Biopsy of the Prostate.; 2011.

23. Saito S. Prostate-specific antigen cut-off point of $2.5 \mathrm{ng} / \mathrm{mL}$ and increasing the number of prostate biopsies results in the detection of curable prostate cancer even in Japanese population. Int J Urol. 2007;14(8):709-12.

24. Djavan B, Waldert M, Zlotta A, Dobronski P, Seitz C, Remzi M, et al Safety and morbidity of first and repeat transrectal ultrasound guided prostate needle biopsies: results of a prospective European prostate cancer detection study. J Urol. 2001;166(3):856-60.

25. Ecke TH, Gunia S, Bartel P, Hallmann S, Koch S, Ruttloff J. Complications and risk factors of transrectal ultrasound guided needle biopsies of the prostate evaluated by questionnaire. Urol Oncol. 2008;26(5):474-8.

26. Simsir A, Kismali E, Mammadov R, Gunaydin G, Cal C. Is it possible to predict sepsis, the most serious complication in prostate biopsy? Urol Int. 2010;84(4):395-9.

27. Eichler K, Hempel S, Wilby J, Myers L, Bachmann LM, Kleijnen J. Diagnostic value of systematic biopsy methods in the investigation of prostate cancer: a systematic review. J Urol. 2006;175(5):1605-12.

28. Levine MA, Ittman M, Melamed J, Lepor H. Two consecutive sets of transrectal ultrasound guided sextant biopsies of the prostate for the detection of prostate cancer. J Urol. 1998;159(2):471-5.

29. Egawa S, Matsumoto K, Shitara T, Uchida T, Kuwao S, Koshiba 
K. Zonal biopsy in the detection of prostate cancer in Japanese men.Jpn J Clin Oncol.1998;28(1):20-6.

30. Eskew LA, Bare RL, McCullough DL. Systematic 5 region prostate biopsy is superior to sextant method for diagnosing carcinoma of the prostate. J Urol.1997;157(1):199-202.

31. Tobiume M, Yamada Y, Nakamura K, Honda N. Retrospective study comparing six- and twelve-core prostate biopsy in detection of prostate cancer. Int Braz J Urol. 2008;34(1):9-14.

32. Ghafoori M, Shakiba M, Seifmanesh H, Hoseini K. Decrease in infection rate following use of povidone-iodine during transrectal ultrasound guided biopsy of the prostate: a double blind randomized clinical trial. Iran J Radiol. 2012;9(2):67-70.

33. Thiesler T, Trinkler F, Horcic M, Willi N, Cathomas G, Hailemariam S. Patients with low prostate-specific antigen levels (< or $=4 \mathrm{ng} / \mathrm{ml}$ ) would benefit from a twelve-core biopsy protocol for prostate cancer detection. Urol Int. 2007;78(4):318-22.

34. Jones JS, Patel A, Schoenfield L, Rabets JC, Zippe CD, Magi-Galluzzi C. Saturation technique does not improve cancer detection as an initial prostate biopsy strategy. J Urol. 2006;175(2):485-8.

35. Kojima M, Hayakawa T, Saito T, Mitsuya H, Hayase Y. Transperineal 12-core systematic biopsy in the detection of prostate cancer. Int J Urol. 2001;8(6):301-7.
36. Matsumoto K, Satoh T, Egawa S, Shimura S, Kuwao S, Baba S. Efficacy and morbidity of transrectal ultrasound-guided 12-core biopsy for detection of prostate cancer in Japanese men. Int J Urol. 2005;12(4):353-60.

37. Terris MK, Wallen EM, Stamey TA. Comparison of mid-lobe versus lateral systematic sextant biopsies in the detection of prostate cancer. Urol Int. 1997;59(4):239-42.

38. Taylor J3, Gancarczyk KJ, Fant GV, McLeod DG. Increasing the number of core samples taken at prostate needle biopsy enhances the detection of clinically significant prostate cancer. Urology. 2002;60(5):841-5.

39. Naughton CK, Miller DC, Mager DE, Ornstein DK, Catalona WJ. A prospective randomized trial comparing 6 versus 12 prostate biopsy cores: impact on cancer detection. JUrol. 2000;164(2):388-92.

40. Sugishita K, Harabayashi T, Furuno T, Suzuki S, Shinohara N, Nonomura K. [Transrectal biopsy of the prostate for the detection of non-palpable prostate cancer: a comparison of 6 versus 12 core biopsy]. Nihon Hinyokika Gakkai Zasshi. 2006;97(6):782-5.

41. Simon J, Kuefer R, Bartsch GJ, Volkmer BG, Hautmann RE, Gottfried HW. Intensifying the saturation biopsy technique for detecting prostate cancer after previous negative biopsies: a step in the wrong direction. BJU Int. 2008;102(4):459-62. 